D. -G. Geng • S. -Y. Liu - A. Steck - G. Eisenbarth •

M. Rewers $\cdot$ J. -X. She

\title{
Comment on: Biason-Lauber A, Boehm B, Lang-Muritano M, et al (2005) Association of childhood type 1 diabetes mellitus with a variant of PAX4: possible link to beta cell regenerative capacity. Diabetologia 48:900-905
}

Received: 22 August 2005 / Accepted: 1 September 2005 / Published online: 16 December 2005

(C) Springer-Verlag 2005

Keywords Association - Genetic heterogeneity - Genetics · PAX4 - Type 1 diabetes

To the Editor: Type 1 diabetes probably results from the imbalance between selective autoimmune destruction of pancreatic beta cells and their regeneration. PAX4, a member of the PAX family of transcription factors, is essential to the differentiation and function of beta cells. Pax 4 knock-out mice showed an absence of mature insulinproducing beta cells and a severe diabetic syndrome after birth [1]. In the May 2005 issue of Diabetologia, BiasonLauber and co-workers reported a strong association between type 1 diabetes and the A1168C (P321H) single nucleotide polymorphism (SNP) in exon 9 of $P A X 4$, both in a Swiss and in a German population [2]. The authors also showed that the PAX4 proteins encoded by the two variants have differential binding affinity to the PAX4 binding site in the insulin promoter [2]. The functional relevance of the SNP and the reported association made it a very attractive candidate mutation; however, these observations need to be confirmed in other populations, because despite their power

D. -G. Geng · S. -Y. Liu · J. -X. She $(\bowtie)$

Center for Biotechnology and Genomic Medicine,

Medical College of Georgia, Room CA4124,

1120 15th Street,

Augusta, GA 30912, USA

e-mail: jshe@mail.mcg.edu

Tel.: +1-706-7213410

Fax: +1-706-7213688

\section{S. Y. Liu}

Key Laboratory of Development Biology in Education

Department, College of Life Science, Wuhan University, Wuhan, China

\section{A. Steck - G. Eisenbarth - M. Rewers}

Barbara Davies Center for Childhood Diabetes,

University of Colorado,

Denver, CO, USA in identifying type 1 diabetes and other complex disease genes, associations observed in case/control studies can be caused by mismatch of ethnicity and other factors.

In an attempt to confirm the PAX4 association with type 1 diabetes, we analysed the A1168C SNP in two large American Caucasian populations. A 398 bp fragment containing the A1168C SNP within the coding region of the PAX4 gene was amplified using the forward primer hPAX4F (5'-TGTCTCAGCCTCTCTCCCATAGTG-3') and the reverse primer hPAX4R (5'-CTCCAATCAGGTGATGCGC CAG- $\left.3^{\prime}\right)$. The amplified products were digested using the restriction enzyme BsaJ I and the digested products were resolved on $2.5 \%$ agarose gels. The uncut $1168 \mathrm{~A}$ allele corresponds to a 398-bp band and the cut $1168 \mathrm{C}$ allele yields two fragments ( 244 and $158 \mathrm{bp}$ ).

The study subjects consisted of Caucasians from two US populations (North-Central Florida and Denver, Colorado). The Florida data set included 322 type 1 diabetes patients and 961 control subjects, while the Denver data set included 630 type 1 diabetes patients and 666 control subjects. These patients and control subjects have been used in our previous genetic studies [3-5]. All diabetic patients were diagnosed using the criteria of the National Diabetes Data Group and the control subjects were healthy and had no family history of type 1 diabetes and no islet cell autoantibodies.

The genotypic frequencies for the A1168C SNP are presented in Table 1. The control and patient populations from both Florida and Denver were found to be in HardyWeinberg equilibrium (Table 1). The frequencies for the PAX4 A1168C genotypes were similar in the Florida and Denver populations. More importantly, there was no significant difference between type 1 diabetic patients and control subjects in either population. Our data from two large Caucasian data sets, therefore, do not support the previously reported association between $P A X 4$ and type 1 diabetes.

It is unlikely that the lack of association is due to the sample size, because our data sets are much larger than those in the previous study. In addition, our sample sets have been used in previous studies, which found significant 
Table 1 Frequency of the A1168C variant of PAX4 in American Caucasian populations

\begin{tabular}{lllll}
\hline & \multicolumn{2}{c}{ Genotypes } & HWE $p$ \\
Subjects & $\mathrm{A} / \mathrm{A}$ & $\mathrm{A} / \mathrm{C}$ & $\mathrm{C} / \mathrm{C}$ & value \\
\hline Florida population & & & & \\
Patients $(n=322)$ & $16(5.0 \%)$ & $103(32.0 \%)$ & $203(63.0 \%)$ & 0.53 \\
Controls $(n=961)$ & $43(4.5 \%)$ & $321(33.4 \%)$ & $597(62.1 \%)$ & 0.98 \\
$p$ value & 0.71 & 0.64 & 0.77 & \\
Denver population & & & \\
Patients $(n=630)$ & $27(4.3 \%)$ & $221(35.1 \%)$ & $382(60.6 \%)$ & 0.48 \\
Controls $(n=666))$ & $27(4.0 \%)$ & $243(36.5 \%)$ & $396(59.5 \%)$ & 0.17 \\
$p$ value & 0.83 & 0.60 & 0.67 & \\
\hline
\end{tabular}

$H W E$, Hardy-Weinberg equilibrium

association with several other genes linked with type 1 diabetes, including HLA, PTPN22, INS and others [3-5]. The discrepancy between our data and the report by Biaison-Lauber et al. may be explained by genetic heterogeneity for the association between PAX4 and type 1 diabetes. However, the associations reported there were possibly spurious and may not reflect a causal relation between PAX4 and type 1 diabetes, since two other studies $[6,7]$, in addition to this report, were unable to confirm the association. Furthermore, the departure from HardyWeinberg equilibrium in both control populations studied in the initial report may indicate major genotyping errors [8]. Therefore, it is reasonable to conclude that PAX4 is unlikely to be a susceptibility gene for type 1 diabetes.
Acknowledgements The authors wish to thank Dr Robert Podolsky for statistical analysis and critical discussions. This study was supported in part by a grant from the National Institute of Child Health and Development (2RO1HD37800) to J. -X. She and R01 DK 32493 to M. Rewers.

\section{References}

1. Sosa-Pineda B (2004) The gene Pax4 is an essential regulator of pancreatic beta-cell development. Mol Cells 18:289-294

2. Biason-Lauber A, Boehm B, Lang-Muritano M et al (2005) Association of childhood type 1 diabetes mellitus with a variant of PAX4: possible link to beta cell regenerative capacity. Diabetologia 48:900-905

3. Guo D, Li M, Zhang Y et al (2004) A functional variant of SUMO4, a new I kappa B alpha modifier, is associated with type 1 diabetes. Nat Genet 36:837-841

4. Zheng W, She JX (2005) Genetic association between a lymphoid tyrosine phosphatase (PTPN22) and type 1 diabetes. Diabetes 54:906-908

5. Steck AK, Bugawan TL, Valdes AM et al (2005) Association of non-HLA genes with Type 1 diabetes autoimmunity. Diabetes 54:2482-2486

6. Maier LM, Cooper JD, Walker N, Smyth DJ, Todd JA (2005) Comment to: Biason-Lauber A, Boehm B, Lang-Muritano M et al (2005) Association of childhood type 1 diabetes mellitus with a variant of PAX4: possible link to beta cell regenerative capacity. Diabetologia 48:900-905. Diabetologia 48:2180

7. Gylvin T, Bergholdt R, Nerup J, Pociot F (2005) To: BiasonLauber A, Boehm B, Lang-Muritano M et al (2005) Association of childhood type 1 diabetes mellitus with a variant of PAX4: possible link to beta cell regenerative capacity. Diabetologia 48:900-905. Diabetologia 48:2183

8. Paterson AD (2005) To: Biason-Lauber A, Boehm B, LangMuritano $M$ et al (2005) Association of childhood type 1 diabetes mellitus with a variant of PAX4: possible link to beta cell regenerative capacity. Diabetologia 48:900-905. Diabetologia 48:2179 